\title{
Girdin regulates the proliferation and apoptosis of pancreatic cancer cells via the PI3K/Akt signalling pathway
}

\author{
SHENG WANG $^{1 *}$, YIQUN LEI ${ }^{*}$, ZELING CAI $^{1}$, XIAOMAN YE $^{2}$, \\ LIANHONG $\mathrm{LI}^{1}$, XIAGANG LUO ${ }^{1}$ and CHUNZHAO YU ${ }^{1}$ \\ ${ }^{1}$ Department of General Surgery, The Second Clinical Medical School of Nanjing Medical University; \\ ${ }^{2}$ Department of Gerontology, Jiangsu Province Hospital, Nanjing, Jiangsu 210029, P.R. China
}

Received January 6, 2018; Accepted May 25, 2018

DOI: $10.3892 /$ or.2018.6469

\begin{abstract}
Girdin functions as an Akt phosphorylation enhancer (APE), which expedites the proliferation and survival of many types of tumours. However, the influence of Girdin on pancreatic cancer and the underlying molecular mechanisms have yet to be uncovered. Hence, in the present study, we sought to elucidate the function of Girdin in pancreatic cancer malignancy, particularly its role in pancreatic cancer cell proliferation, migration and apoptosis. Immunohistochemistry (IHC) was used to evaluate Girdin expression in pancreatic cancer tissues and to analyse its correlation with pathological grade. Girdin expression was further validated in pancreatic cancer cell lines (AsPC-1, BxPC-3 and PANC-1), and human pancreatic ductal epithelial (HPNE) cells were used as a control. Recombinant adenovirus vectors containing Girdin-siRNA were constructed to inhibit Girdin expression and were used in subsequent experiments to determine the effects of Girdin silencing on pancreatic cancer cells. Girdin silencing suppressed pancreatic cancer cell proliferation and induced pancreatic cancer cell apoptosis in vitro and in vivo. According to the results of further mechanistic investigations, Girdin may regulate cell
\end{abstract}

Correspondence to: Professor Chunzhao Yu, Department of General Surgery, The Second Clinical Medical School of Nanjing Medical University, 121 JiangJiaWei, Nanjing, Jiangsu 210029, P.R. China

E-mail: chunzhaoyu@hotmail.com

*Contributed equally

Abbreviations: Akt, protein kinase B; APE, Akt phosphorylation enhancer; Bax, apoptosis regulator; Bcl-2, member of a family of apoptosis regulators; caspase-3, member of a family of apoptosis regulators; P21, cyclin-dependent kinase inhibitor 1A; P15, regulator of cyclin-dependent kinases; cyclin-D1, regulator of cyclin-dependent kinases; PI3K, phosphatidylinositol-3-kinase; IHC, immunohistochemistry; PDAC, pancreatic ductal adenocarcinoma; SRB, sulforhodamine B

Key words: pancreatic cancer, Girdin, proliferation, apoptosis, PI3K/Akt signalling pathway processes through the phosphatidylinositol-3-kinase/protein kinase $\mathrm{B}$ (PI3K/Akt) signalling pathway to exert additive effects on pancreatic cancer.

\section{Introduction}

Pancreatic cancer is one of the most common causes of cancer-related death in humans and is characterized by high malignant potential and poor patient prognosis. Over $50 \%$ of patients with pancreatic cancer present with distant metastasis at diagnosis, and the 5-year survival rate is less than $8 \%$ in the US (1). Similarly, a statistical analysis of the incidence and mortality of cancer in China shows that the mortality rate of pancreatic cancer is as high as $88 \%$ (2). Pancreatic ductal adenocarcinoma (PDAC) is currently the most common and highly malignant histological subtype of pancreatic cancer (3). Despite improvements in medicine, the mortality rate of pancreatic cancer has not significantly improved in the past few decades. On one hand, its unique anatomical location makes the disease difficult to diagnose. On the other hand, most patients acquire resistance to chemotherapy. Therefore, an understanding of the biological characteristics and molecular mechanisms of pancreatic cancer and the identification of new therapeutic targets are current objectives and challenges.

Girdin was first reported by Japanese scientists (4); due to its role in regulating intracellular microfilaments, some researchers refer to it as 'girders of actin filaments'. Girdin has been shown to play an important role in the occurrence and development of many tumours. Girdin has been reported to be expressed at high levels in breast, colon and cervical cancer, and many other malignant tumours (5-7). Additionally, Girdin participates in tumour cell metastasis, angiogenesis and the regulation of autophagy (8-10). As a substrate of Akt, Girdin enhances the phosphorylation of Akt and induces its activation; therefore, it is also known as an Akt phosphorylation enhancer (APE) (11). The P13K/Akt signalling pathway regulates various processes in numerous tumour cells (12); Girdin may also be involved in this process. However, evidence showing that Girdin plays a role in the development of pancreatic cancer is not available.

In the present study, we aimed to determine the correlation between Girdin expression and the development of 
pancreatic cancer as well as to confirm the effects of Girdin on the proliferation, migration, apoptosis and cell cycle of pancreatic cancer cells via recombinant adenovirus-induced Girdin silencing. Our research seeks to elucidate the P13K/Akt signalling pathway-mediated functions of Girdin in pancreatic cancer and may help further advance the treatment of pancreatic cancer and identify novel biomarkers.

\section{Materials and methods}

Cell culture and adenoviral infection. Human pancreatic ductal epithelial cells (hTERT-HPNE) and human pancreatic cancer cell lines (AsPC-1, BxPC-3 and PANC-1) were acquired from the American Type Culture Collection (ATCC; Manassas, VA, USA). AspC-1 cells were cultured in RPMI-1640 medium (Gibco; Thermo Fisher Scientific, Inc., Waltham, MA, USA), whereas the other cell lines were maintained in Dulbecco's modified Eagle's medium (DMEM; Gibco; Thermo Fisher Scientific, Waltham, MA, USA) supplemented with $10 \%$ fetal bovine serum (FBS) (Wisent, St-Bruno, QC, Canada) at $37^{\circ} \mathrm{C}$ in a humidified atmosphere containing $5 \% \mathrm{CO}_{2}$.

Recombinant adenoviruses containing the Girdin shRNA (rAd-shGirdin) and an empty vector (rAd-GFP) were synthesized using the vector pAd-U6-CMV-GFP (Shanghai Lici Biotechnology, Shanghai, China). 293A cells (ATCC) were used to package the recombinant adenovirus. The empty rAd-GFP vector was constructed as an experimental control.

Immunohistochemistry (IHC) and tissue microarray. Pancreatic cancer tissue microarrays were created by Xian Ailina Biotechnology Co., Ltd. (Xi'an, Shanxi, China). Girdin expression was observed by staining tissues with streptavidin-biotin complex (SAB). Girdin staining in human tissues was independently scored by two pathologists using a semi-quantitative immunoreactivity score (IRS), as previously described (13). Based on the scoring system, tissues with an IRS of 0-5 and 6-9 were defined as expressing low and high levels of Girdin, respectively.

Western blot analysis. Cells were washed twice with cold phosphate-buffered saline (PBS) and then solubilized in RIPA lysis buffer. Cell debris was removed by centrifugation at $12,000 \mathrm{x} \mathrm{g}$ for $15 \mathrm{~min}$ at $4^{\circ} \mathrm{C}$, and the supernatants were collected. Samples with the same amount of protein $(30 \mu \mathrm{g})$ were subjected to sodium dodecyl sulphate-polyacrylamide gel electrophoresis (SDS-PAGE) and transferred to polyvinylidene fluoride (PVDF) membranes (Millipore, Billerica, MA, USA). Membranes were blocked in Tris-buffered saline containing $0.05 \%$ Tween-20 (TBST) and 5\% bovine serum albumin (BSA; Sigma-Aldrich; Merck KGaA, Darmstadt, Germany) for $2 \mathrm{~h}$ at room temperature, followed by incubation with primary antibodies overnight and a subsequent incubation with horseradish peroxidase-conjugated secondary antibodies for $2 \mathrm{~h}$ at room temperature. Antibodies against p-Akt (1:1,000, cat. no. 4060), Akt (1:1,000; cat. no. 4685), caspase-3 (1:1,000, cat. no. 9662), cleaved caspase-3 (1:1,000; cat. no. 9664) and cyclin D1 (1:1,000; cat. no. 2978) were purchased from Cell Signaling Technology, Inc. (Beverly, MA, USA). Antibodies against Girdin (1:1,000; cat. no. ab179481), Bcl-2 (1:1,000; cat. no. ab196495) and
BAX (1:1,000; cat. no. ab53154) were purchased from Abcam (Cambridge, UK). Antibodies against phosphorylated Girdin (S1416) (1:250; cat. no. 28067) were purchased from IBL (Immuno-Biological Laboratories Co., Ltd., Gunma, Japan). GAPDH (1:1,000; cat. no. sc-47724), $\beta$-actin $(1: 1,000$; cat. no. 47778) and goat anti-rabbit IgG antibodies (1:30,000; cat. no. sc-2004) were acquired from Santa Cruz Biotechnology, Inc. (Santa Cruz, CA, USA).

Total RNA isolation and quantitative real-time polymerase chain reaction $(q P C R)$. Total RNA was isolated using Invitrogen $^{\mathrm{TM}}$ TRIzol reagent (Thermo Fisher Scientific, Inc., Waltham, MA, USA) and cDNAs were synthesized according to the manufacturer's instructions (Takara Bio, Inc., Otsu, Japan). Equal amounts of cDNAs were subjected to PCR analysis. The primers used for RT-PCR (Invitrogen; Thermo Fisher Scientific, Inc.) were: Girdin (forward), 5'-AGGAAA TGGGACCAACCTTGA-3' and Girdin (reverse), 5'-GTG CATTCTAAGTGAGGCATCAT-3'; GAPDH (forward), 5'-AGAAGGCTGGGGCTCATTTG-3' and GAPDH (reverse), 5'-AGGGGCCATCCACAGTCTTC-3'.

Cell proliferation assay. Cells were seeded onto 96-well dishes at a density of $1 \times 10^{4}$ cells/well. Cell viability was determined using sulforhodamine B (SRB) assays after the cells were incubated with rAd-shGirdin for 24,48 or $72 \mathrm{~h}$. Subsequently, the 96-well dishes were taken out and fixed with trichloroacetic acid for $3 \mathrm{~h}$ at room temperature followed by staining with SRB solution for another $15 \mathrm{~min}$. Then, the 96-well dishes were washed and $10 \mathrm{mmol} / \mathrm{l}$ Tris-base $(\mathrm{pH}=10.5)$ was used to solubilize the protein-bound dye, and finally, a spectrophotometer was used to measure the absorbance at $490 \mathrm{~nm}$, which indicated the cell proliferation rate.

Colony formation assay. Cells were seeded in triplicate wells of 6-well plates at a density of 50 cells/well. After 10-14 days, colonies were clearly visible, and the cells were fixed with $1 \%$ trichloroacetic acid overnight at $4^{\circ} \mathrm{C}$ and stained with SRB. Colonies containing $>50$ cells were counted under a light microscope (Olympus IX51+DP72; Olympus Corp., Tokyo, Japan).

Terminal deoxynucleotidyl transferase dUTP nick end labelling (TUNEL) assay. The TUNEL BrightRed Apoptosis Detection kit (Vazyme, Piscataway, NJ, USA) was used to detect apoptotic pancreatic cancer cells according to the manufacturer's instructions.

Cell cycle and apoptosis analyses using flow cytometry. Aliquots of cells were collected from the control and synchronized cultures and suspended in $70 \%$ ethanol overnight at $-20^{\circ} \mathrm{C}$. Fixed cells were washed with PBS, suspended in $4 \mathrm{mM}$ sodium citrate containing $30 \mathrm{U} / \mathrm{ml}$ RNase A, $0.1 \%$ Triton $\mathrm{X}-100$ and $50 \mu \mathrm{g} / \mathrm{ml}$ propidium iodide (PI), and then incubated for $30 \mathrm{~min}$ at $37^{\circ} \mathrm{C}$ in the dark prior to the flow cytometric analysis. Data were collected using a FACScan apparatus (BD Biosciences, San Jose, CA, USA), and the results were analysed using BD CellQuest software.

Apoptosis was detected by flow cytometry. Cells were incubated with a recombinant adenovirus, LY294002, or both 
A

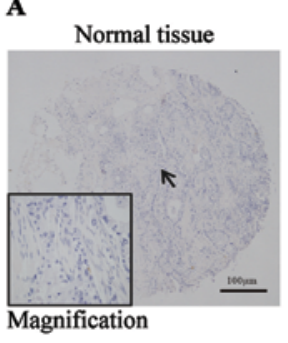

C

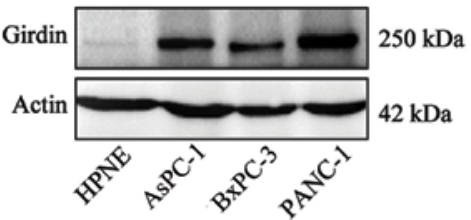

B

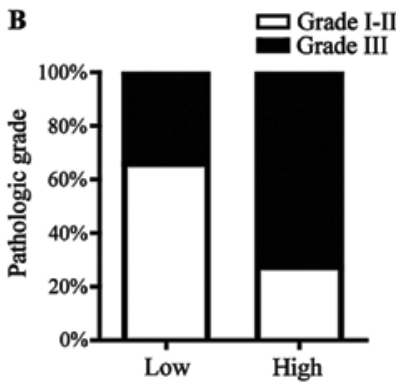

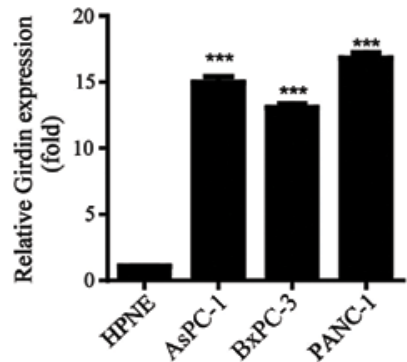

Figure 1. Statistical analysis of the correlation between Girdin expression and pancreatic cancer. (A) Immunohistochemical staining for Girdin in normal human pancreas tissue $(\mathrm{n}=51)$ and pancreatic cancer tissue $(\mathrm{n}=90)$. Scale bar, $100 \mu \mathrm{m}$. (B) High Girdin expression is correlated with a higher pathological grade. (C) Girdin is overexpressed in the PDAC cell lines AsPC-1, BxPC-3 and PANC-1, as shown by western blotting. Bars represent the SEM. ${ }^{* * *} \mathrm{P}<0.001$. Three separate experiments were performed.

simultaneously, and then washed twice with ice-cold PBS, and resuspended in 1X binding buffer (BD Pharmingen; BD Biosciences, Franklin Lakes, NJ, USA). Subsequently, $5 \mu \mathrm{l}$ of 7-AAD (BDPharmingen; BD Biosciences) and $5 \mu$ of APC (BD Pharmingen; BD Biosciences) were added. Finally, the samples were analysed using a flow cytometer (BD FACS Calibur equipped with Cell Quest Pro software).

Immunofluorescence staining. Cells were fixed with $4 \%$ paraformaldehyde overnight at $4^{\circ} \mathrm{C}$, washed 3 times with PBS, and incubated with PBS containing $0.1 \%$ Triton and $5 \mathrm{mg} / \mathrm{ml} \mathrm{BSA}$. Then, cells were blocked with $5 \% \mathrm{BSA}$ for $30 \mathrm{~min}$ at $37^{\circ} \mathrm{C}$. The cells were then stained with antibodies against p-Akt (1:100; Bioss, Beijing, China) and p-Girdin (1:100; IBL, Gunma, Japan) overnight at $4^{\circ} \mathrm{C}$, and subsequently incubated with a fluorescent dye-conjugated goat anti-rabbit IgG (Thermo Fisher Scientific, Inc.) for $30 \mathrm{~min}$ at $37^{\circ} \mathrm{C}$. Nuclei were stained with DAPI (Sigma-Aldrich; Merck KGaA, Darmstadt, Germany). Images were captured using a confocal laser scanning microscope (Olympus Corp.).

Tumour xenograft model. Sixteen nu/nu mice (females, 6 weeks of age, 13-15 g; Beijing Vital River Laboratory Animal Technology Co., Ltd., Beijing, China) were housed in sterile cages by conventional feeding. The left flank of each mouse was subcutaneously injected with BxPC-3 cells (5x10 $0^{6}$ cells $\left./ 100 \mu \mathrm{l} \mathrm{PBS}\right)$ to establish the pancreatic cancer xenograft model. Five days after the subcutaneous inoculation, the mice were randomly divided into different groups for different sets of experiments. Cells were infected with rAd-shGirdin prior to subcutaneous inoculation. LY294002 was intraperitoneally injected at a dose of $25 \mathrm{mg} / \mathrm{kg} /$ day [dissolved in dimethyl sulphoxide (DMSO)] twice per week for 3 weeks. Tumour volumes were observed every 3 days and were

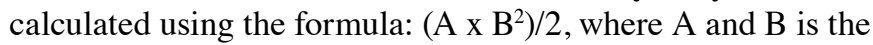

long and short dimensions, respectively. Mice were sacrificed by cervical dislocation on day 21 , and the weights and volumes of the tumours were measured. Half of the tumour specimens were fixed with $4 \%$ paraformaldehyde, and the other half was cryopreserved at $-80^{\circ} \mathrm{C}$. All animals received humane care, and all experiments were performed according to the guidelines outlined in the Guide for the Care and Use of Laboratory Animals, and our experiments were reviewed and approved by the Animal Ethics and Welfare Committee (AEWC) with approval no. IACUC-1601161.

Statistical analysis. All statistical analyses were performed using GraphPad Prism 5.0 software (GraphPad Software, Inc., La Jolla, CA, USA). Each experiment was performed 3 times. All data are expressed as means \pm SEM, unless specified otherwise. Data from each group were statistically analysed using two-tailed Student's t-test, except for the immunohistochemical score, which was analysed using the Chi-square test. However, ANOVA was used for the comparison of multiple groups. Differences were considered statistically significant at $\mathrm{P}<0.05$. $\mathrm{P}$-values indicating statistically significant differences were set to ${ }^{*} \mathrm{P}<0.05,{ }^{* *} \mathrm{P}<0.01$ and ${ }^{* * *} \mathrm{P}<0.001$, as shown in the figures.

\section{Results}

Girdin is overexpressed in pancreatic cancer. Immunohistochemical staining was used to detect Girdin expression in pancreatic cancer. Staining of the pancreatic tissue microarray (including 51 normal pancreatic tissue samples and 90 PDAC samples) showed that none of the normal tissues exhibited Girdin-positive staining, whereas Girdin was overexpressed in approximately $13 \%$ of the PDAC tissues (Fig. 1A and Table I). The immunostaining results were evaluated using a previously described double scoring system (13). Significantly higher 
Table I. Expression of Girdin in human pancreas and pancreatic cancer tissues.

\begin{tabular}{lcccr}
\hline Group & $\mathrm{n}$ & Girdin low expression & Girdin high expression & P-value \\
\hline Normal pancreas tissue & 51 & 51 & 0 & $0.009^{\mathrm{a}}$ \\
PDAC tissue & 90 & 79 & 11 & \\
\hline
\end{tabular}

aSignificant difference. PDAC, pancreatic ductal adenocarcinoma.

A
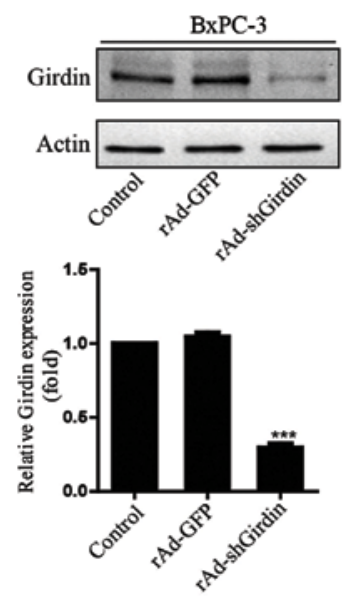

C

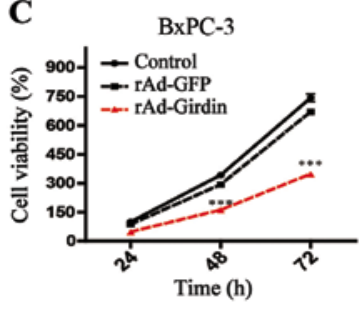

PANC-1

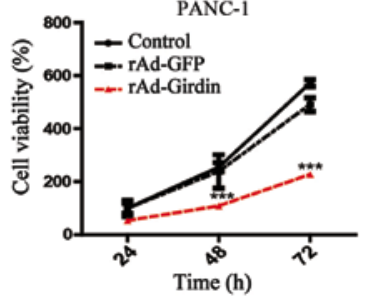

B
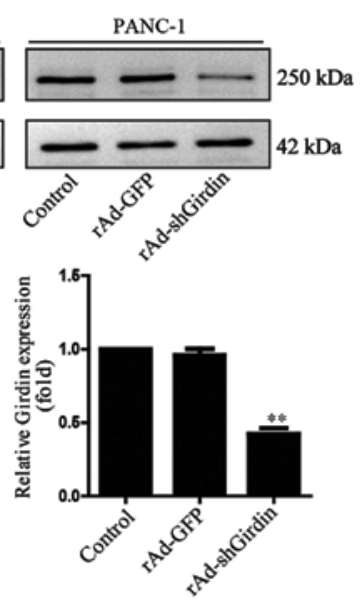

D
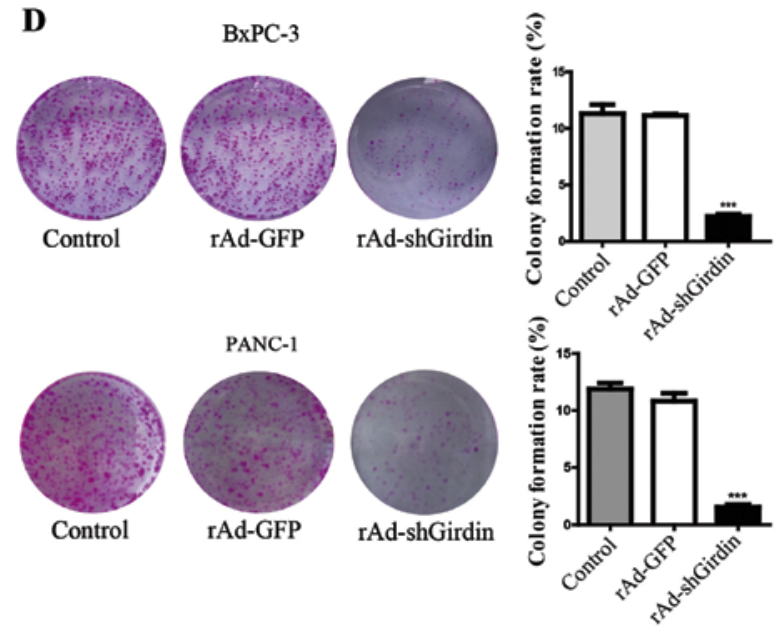

Figure 2. Girdin silencing inhibits pancreatic cancer cell proliferation. (A and B) Western blot analysis and qRT-PCR were performed to evaluate Girdin expression in BxPC-3 and Panc-1 cells infected with rAd-shGirdin. Bars represent the SEM. ${ }^{* *} \mathrm{P}<0.01,{ }^{* * *} \mathrm{P}<0.001$. (C) Girdin silencing reduced cell viability at 24,48 and 72 h. (D) Girdin silencing suppressed the colony-forming capacity of BxPC-3 and PANC-1 cells. Bars represent the SEM. ${ }^{* * * *}<<0.001$. Three separate experiments were performed.

levels of Girdin expression were detected in tumour tissues when compared with that in normal tissues $(\mathrm{P}<0.01)$. Next, we explored the association between high Girdin expression and clinical characteristics. We did not observe significant differences in regards to sex, age or clinical stage. However, Girdin expression was associated with pathological grade, which indicates the differentiation status of cancer. A greater number of grade 3 PDAC tissues displayed high Girdin expression than grades 1-2 ductal adenocarcinoma tissues $(5.4 \%$ of grade 1-2 tissues displayed high expression of Girdin, and $23 \%$ of grade 3 tissues displayed high expression of Girdin; $\mathrm{P}<0.05$ ) (Fig. 1B and Table II). We then analysed Girdin expression in the PDAC cell lines AsPC-1, PANC-1 and BxPC-3 by western blotting and used human pancreatic ductal epithelial (HPNE) cells as a control. As shown in Fig. 1C, higher levels of Girdin expression were detected in pancreatic cancer cells than in HPNE cells. In addition, the levels of Girdin expression differed among the 3 pancreatic cancer cell lines, and BxPC-3 cells exhibited the lowest Girdin expression levels, but these levels were still higher than the levels detected in the HPNE cells $(\mathrm{P}<0.01)$.

Girdin silencing inhibits pancreatic cancer cell proliferation. After confirming that Girdin is overexpressed in pancreatic 
A
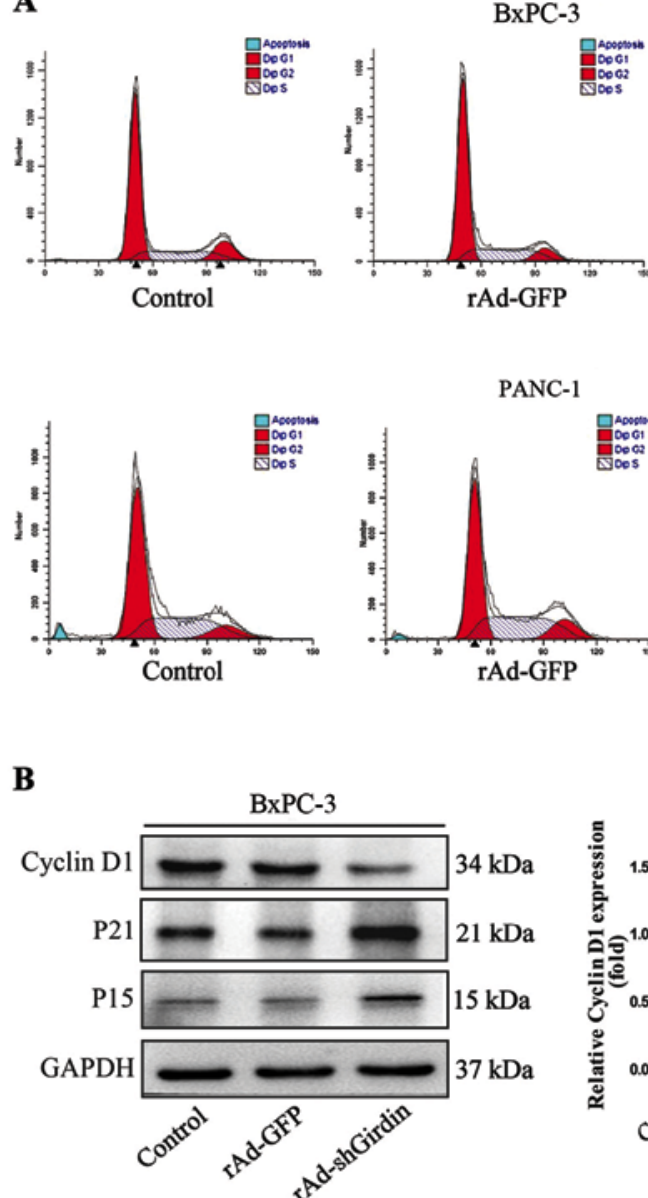

PANC-1

B

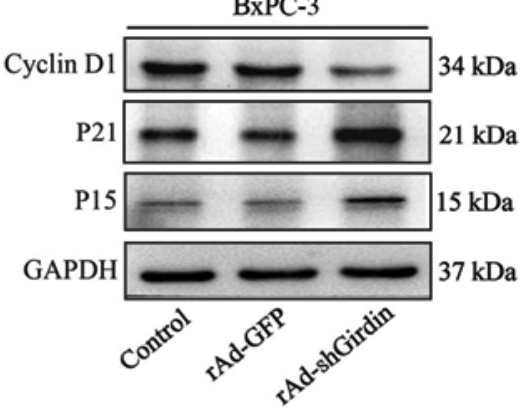

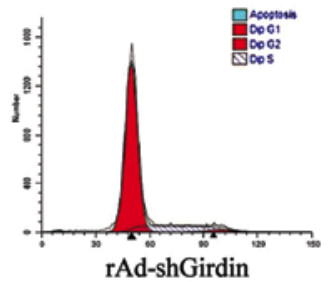
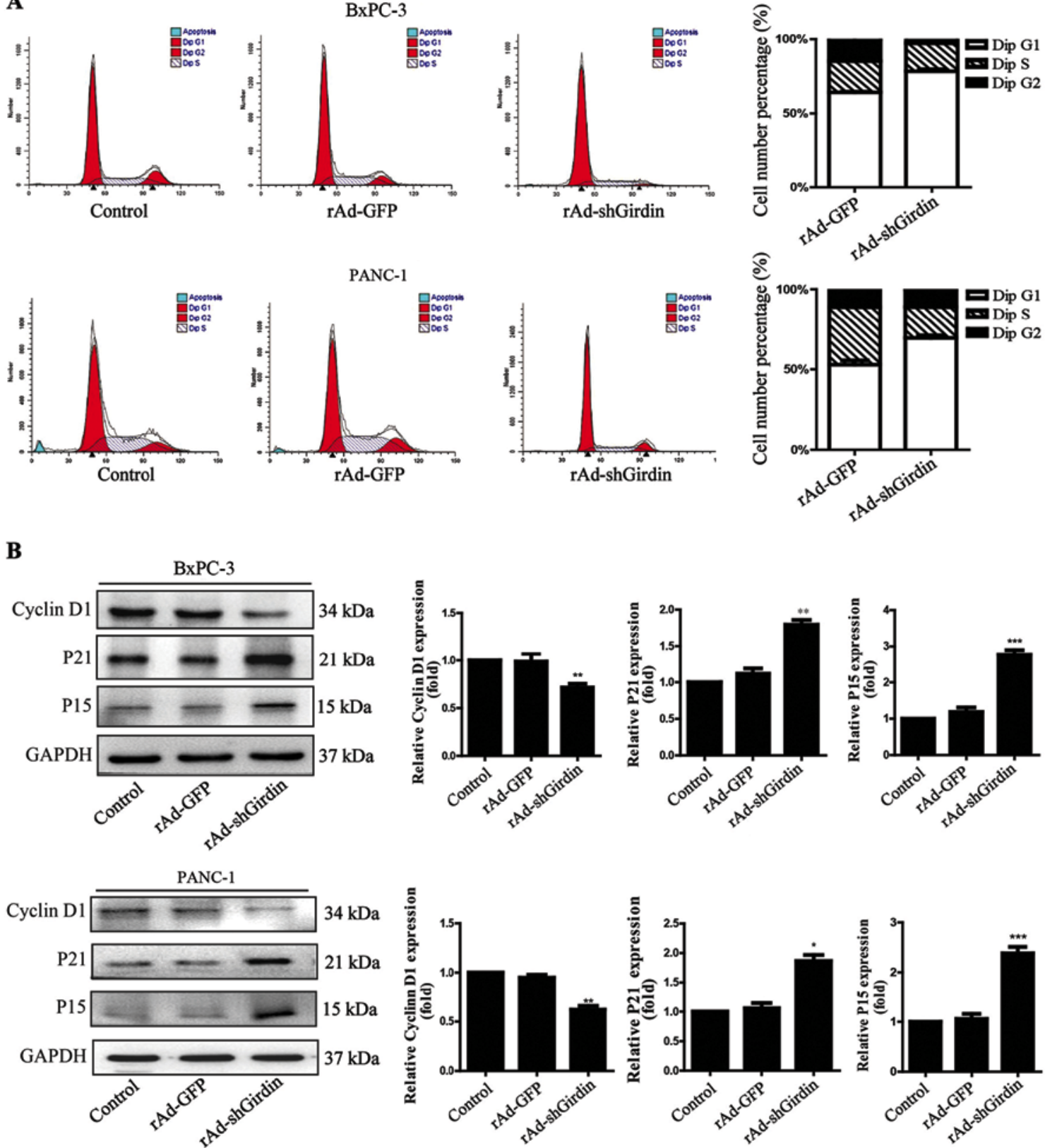

Figure 3. Girdin silencing results in cell cycle arrest. (A) Girdin silencing caused arrest in $\mathrm{G}_{1} / \mathrm{S}$ phase of the cell cycle in BxPC-3 and PANC-1 cells, as shown by flow cytometry. The proportion of BxPC-3 cells in $\mathrm{G}_{1}$ phase increased from $\sim 62$ to $79 \%$, whereas the proportion of PANC-1 cells in $\mathrm{G}_{1}$ phase increased from $\sim 5$ to $71 \% 48 \mathrm{~h}$ after transfection. (B) Western blotting was performed to evaluate the expression of cell cycle-related proteins in BxPC-3 and PANC-1 cells. The data are representative of 3 independent experiments and are expressed as means $\pm \mathrm{SEM} ;{ }^{*} \mathrm{P}<0.05,{ }^{* *} \mathrm{P}<0.01$ and ${ }^{* * * *} \mathrm{P}<0.001$.

cancer, we aimed to ascertain its role in pancreatic cancer development. Thus, we constructed two small interfering RNAs (siRNA-1, nucleotides 145-165; siRNA-2, nucleotides 780-800) and used them to silence Girdin expression, as previously described (4). According to our tests, siRNA2 (sequence target, 780-800) significantly reduced the levels of Girdin mRNA and protein compared with the other siRNA (data not shown). Therefore, siRNA-2 was selected for subsequent applications and was used to construct recombinant adenovirus expression vectors. We infected BxPC-3 and PANC-1 cells with rAd-shGirdin and rAd-GFP, respectively, to determine whether Girdin affects pancreatic cancer. Western blotting (Fig. 2A) and qRT-PCR (Fig. 2B) were used to detect post-infection Girdin expression levels in the rAd-shGirdin, negative control (rAd-GFP) and control group. The BxPC-3 and PANC-1 cells were successfully infected with the recombinant adenoviruses, and Girdin expression was silenced.

An SRB assay was used to determine the changes in cell viability following infection with $\mathrm{rAd}$-shGirdin and evaluate the effect of Girdin downregulation on pancreatic cancer cell proliferation. A significantly lower proliferation rate was observed in the rAd-shGirdin-infected group than in the negative control group (rAd-GFP) and the control group at all time points (48 and $72 \mathrm{~h}$ ), whereas no statistically significant differences were observed between the control group and the negative control group ( $\mathrm{P}<0.01$, Fig. $2 \mathrm{C}$ ). A subsequent colony formation assay further revealed that Girdin silencing inhibited the colony-forming capacity of pancreatic cancer cells 
A
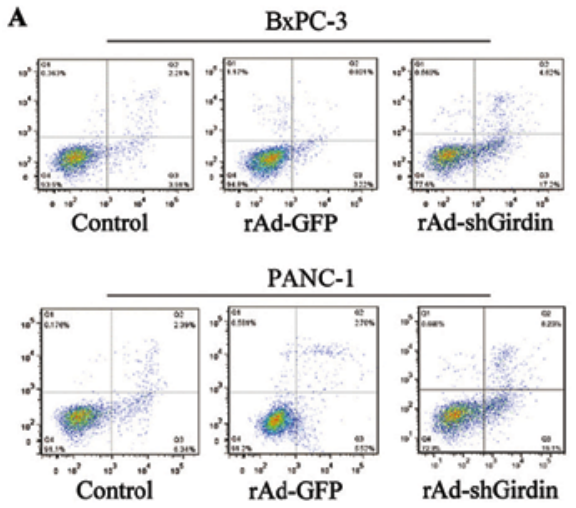

C

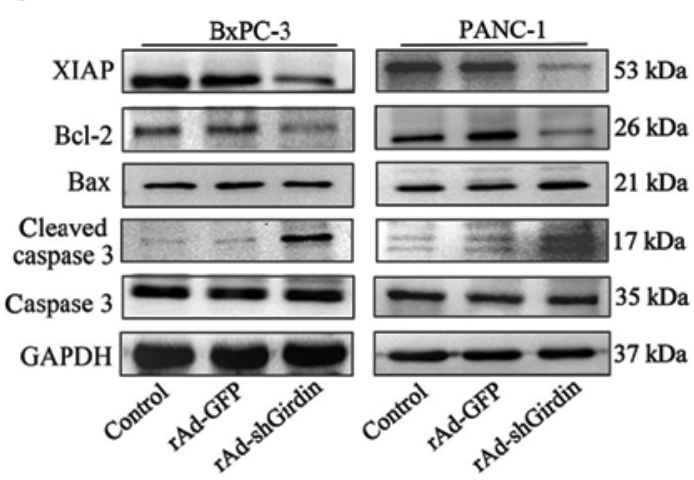

B

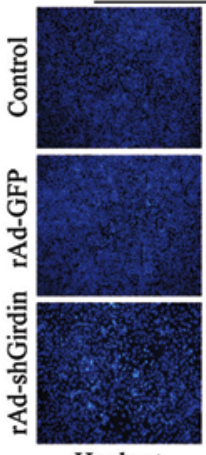

Hochest
BxPC-3

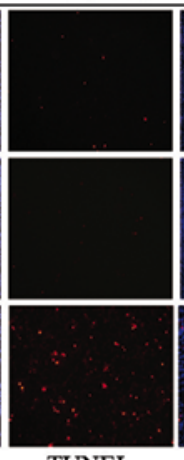

TUNEL

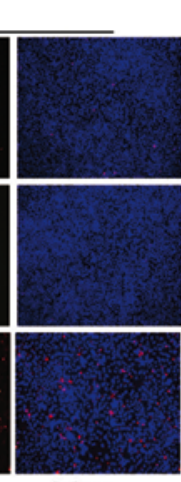

Merge

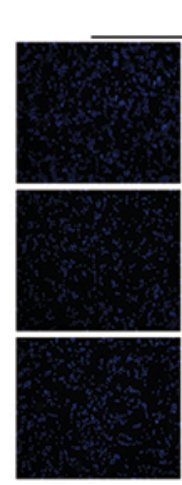

Hochest
PANC-1

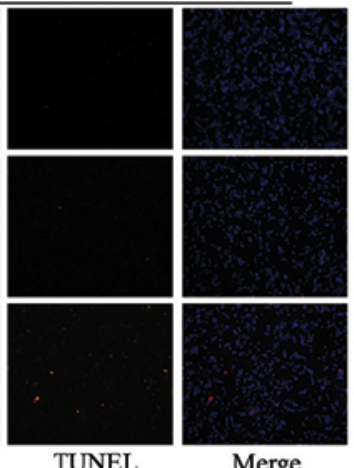

TUNEL

Merge BxPC-3
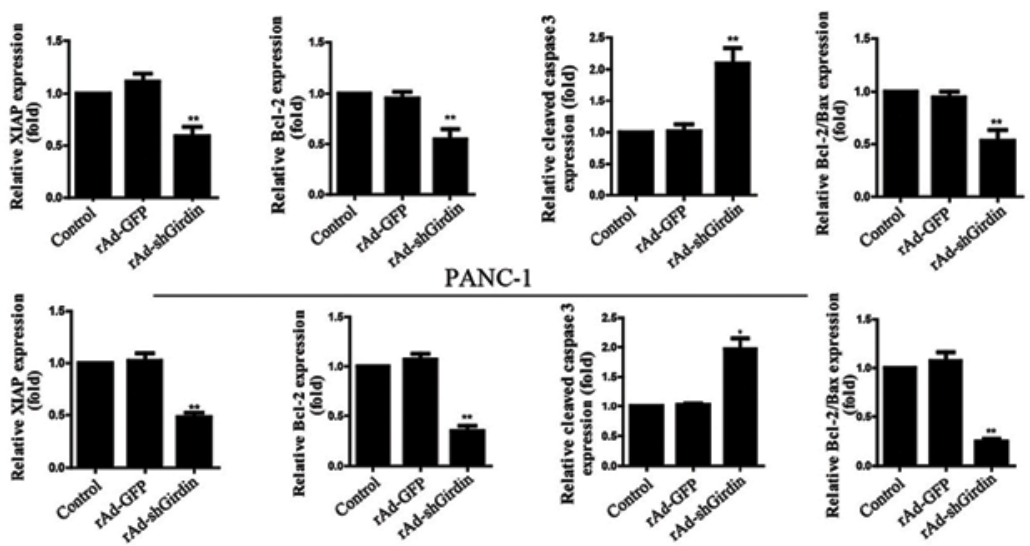

Figure 4. Girdin silencing promotes pancreatic cancer cell apoptosis. (A) Flow cytometry was performed using BxPC-3 and PANC-1 cells transfected with rAd-shGirdin, which significantly induced apoptosis in pancreatic cancer cells. (B) The TUNEL assay showed a higher cell apoptosis rate in BxPC-3 and PANC-1 cells transfected with rAd-shGirdin than in the control and the rAd-GFP group. (C) Western blotting was performed to evaluate the expression of apoptosis-related proteins in BxPC-3 and PANC-1 cells. Each experiment was performed 3 times, and all data are expressed as means \pm SEM; ${ }^{*}<0.05$ and ${ }^{* *} \mathrm{P}<0.01$.

(Fig. 2D). Based on these results, downregulation of Girdin expression inhibits pancreatic cancer cell proliferation.

Girdin silencing arrests the cell cycle and promotes pancreatic cancer cell apoptosis. Inhibition of cell proliferation is caused by a reduction of cell growth, increased apoptosis, or both. Thus, we aimed to ascertain the effect of Girdin silencing on the cell cycle distribution and apoptosis in rAd-shGirdin-infected pancreatic cancer cells. First, flow cytometry was used to detect changes in the cell cycle. As shown in Fig. 3A, at $48 \mathrm{~h}$ after infection, rAd-shGirdin-infected cells were arrested at $G_{1} / S$ phase, suggesting that these cells were unable to complete mitosis in the absence of sufficient Girdin activity. Cells infected with rAd-GFP showed no apparent changes in their cell cycle profiles throughout the experiment. Thereafter, we analysed the expression levels of related proteins following Girdin silencing with rAd-shGirdin by western blotting. Following rAD-shGirdin infection, levels of the P15 and P21 proteins were markedly increased, whereas the level of cyclin D1 was decreased $(\mathrm{P}<0.01$, Fig. 3B), indicating cell cycle arrest. Flow cytometry was also used to detect apoptosis, and cancer cells that had been infected with rAd-shGirdin for $48 \mathrm{~h}$ displayed notably higher apoptosis rates than cells in the rAd-GFP and the control group (Fig. 4A). Moreover, based on the results of the TUNEL assay, Girdin silencing induced pancreatic cancer cell apoptosis (Fig. 4B). We also investigated the levels of proteins involved in several apoptosis-related pathways by western blotting, such as caspase-mediated or Bcl-2 family-mediated pathways. XIAP and Bcl-2 were expressed at lower levels in the Girdin-knockdown group than in the untreated group and negative control group (Fig. 4C), whereas cleaved caspase-3 expression was upregulated; no significant change was detected in caspase- 3 expression. Although Bax expression was not significantly changed, the Bcl-2/Bax ratio was clearly reduced. Thus, Girdin silencing increases pancreatic cancer cell apoptosis.

Girdin plays a crucial role in various processes in pancreatic cancer cells via the PI3K/Akt signalling pathway. As a substrate of Akt, Girdin induces Akt phosphorylation (14). Notably, our previous study confirmed that Akt is also overexpressed in pancreatic cancer (13). The PI3K/Akt pathway is reported to be linked to proliferation, migration and anti-apoptotic signal transduction (15). Hence, we hypothesized that Girdin may influence pancreatic cancer cell processes via the PI3K/Akt pathway. Thus, we first detected changes in the expression of proteins in the PI3K/Akt pathway by western blotting. Following rAd-shGirdin infection, levels of p-PI3K (Thy 508) and p-Akt (Ser 473) proteins were significantly decreased, whereas levels of total PI3k and Akt proteins were not remarkably changed (Fig. 5A). Based on these results, 
$\mathbf{A}$
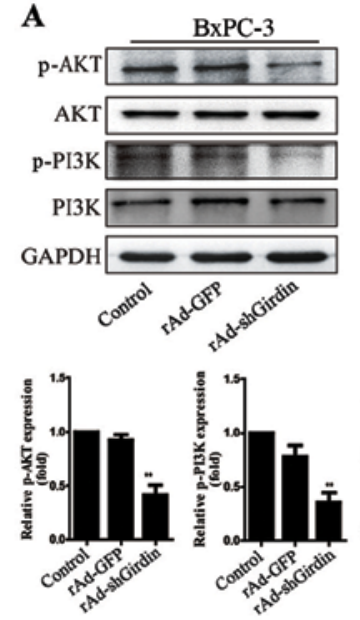

C

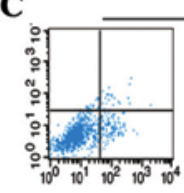

Control
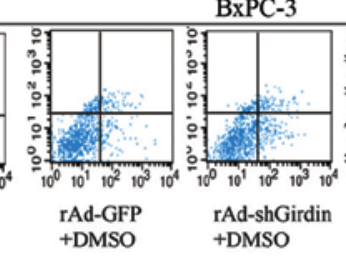

D
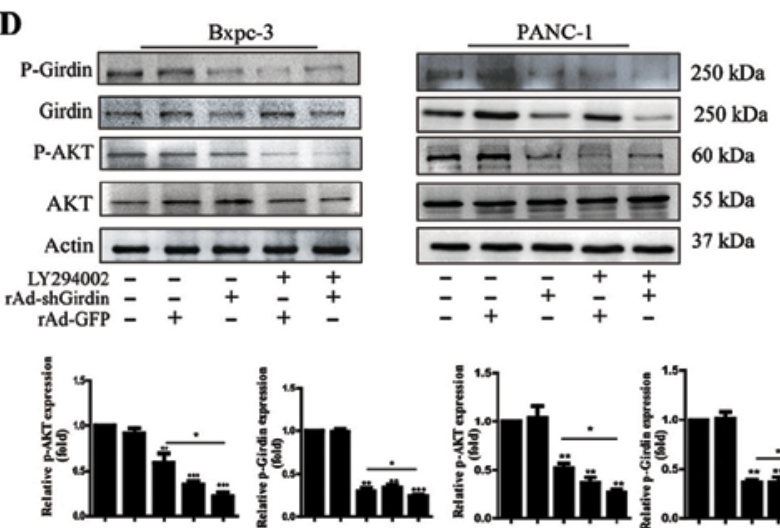
LY294002 $=-++$
rAd-shGirdin $=-+$
TAd-GFP $=+$
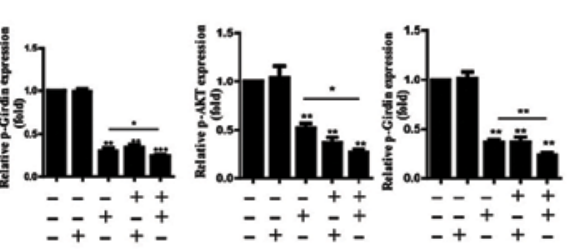

B
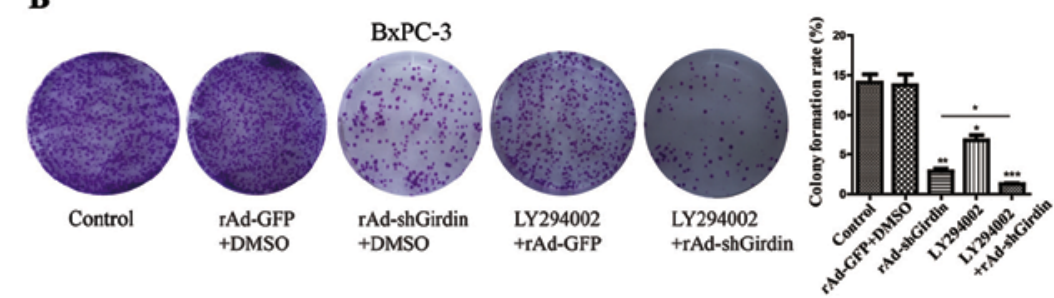

PANC-1
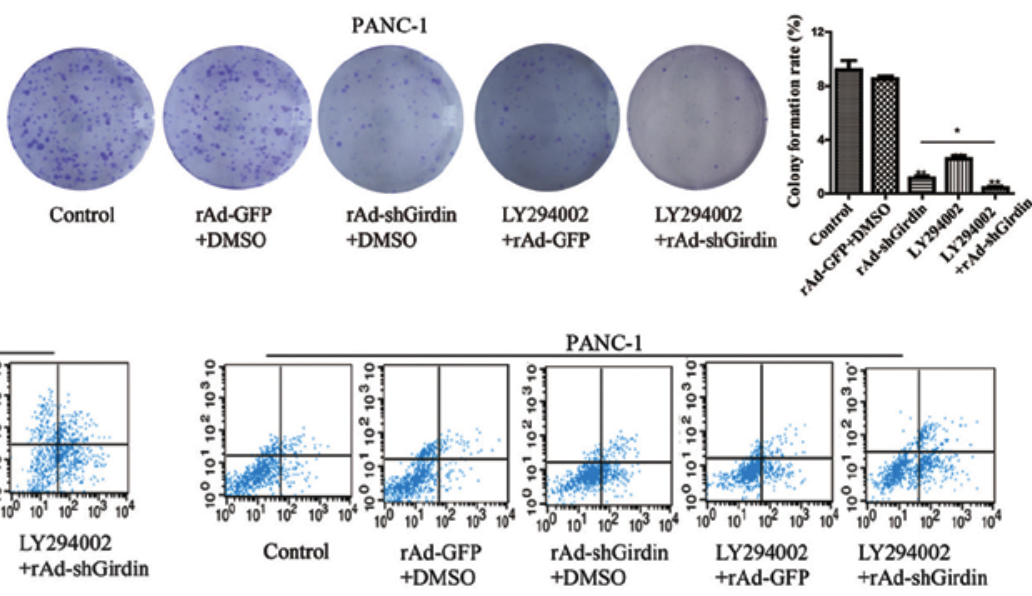

E
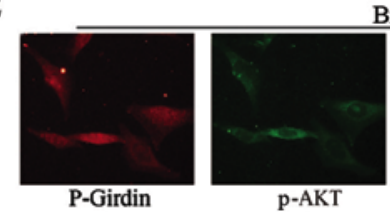

BxPC-3
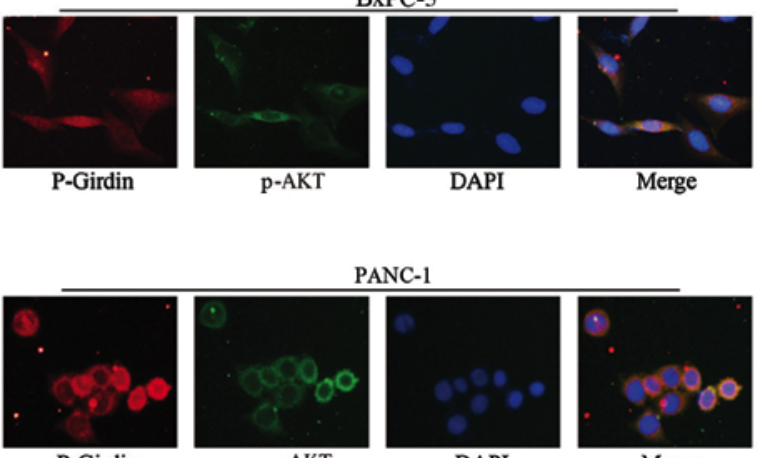

PANC-1

P-Girdin

p-AKT
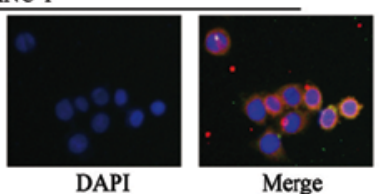

DAP

Merge

Figure 5. Girdin plays a crucial role in pancreatic cancer cell processes via the PI3K/Akt signalling pathway. (A) Western blots of BxPC-3 and PANC-1 cells were performed. Levels of the p-Akt and p-PI3K proteins were decreased in the rAd-shGirdin group, whereas the levels of the Akt and PI3K proteins were not significantly changed compared to the control group. (B) BxPC-3 and PANC-1 cell viability was detected using the colony formation assay. Cells were infected with rAd-shGirdin and subsequently treated with LY294002. (C) Apoptosis of BxPC-3 and PANC-1 cells was detected by flow cytometry. Cells were infected with rAd-shGirdin and subsequently treated with LY294002. (D) Western blots of BxPC-3 and PANC-1 cells were performed. The level of the p-Girdin proteins was decreased in cells treated with LY294002, whereas the level of the Girdin protein was not significantly changed. Treatment with the combination of rAd-shGirdin and LY294002 further decreased the level of p-Girdin. (E) Representative images of immunofluorescence staining show the co-localization of p-Girdin and p-Akt in the cytoplasm. Red represents p-Girdin, green represents p-Akt, and the nuclei were labelled with DAPI, cells were not given any treatment. Each experiment was performed 3 independent times, and all data are expressed as means \pm SEM; ${ }^{*} \mathrm{P}<0.01,{ }^{* * *} \mathrm{P}<0.01$ and ${ }^{* * *} \mathrm{P}<0.001$.

Girdin may affect the activation of the PI3K-Akt signalling pathway. LY294002, an inhibitor of the PI3K/Akt signalling pathway, was used to further verify this finding. According to our previous study, the optimal concentrations of LY294002 for the different pancreatic cancer cell lines were IC $50_{\mathrm{AsPC}-1}=40 \mu \mathrm{M}$, IC $50_{\mathrm{B} \times \mathrm{PC}-3}=15 \mu \mathrm{M}$ and $\mathrm{IC} 50_{\mathrm{PANC}-1}=35 \mu \mathrm{M}$ (13). We added LY294002 to Girdin-knockdown cells to determine whether various processes in pancreatic cancer cells were impacted. As expected, in the colony formation assay, the application of LY294002 combined with Girdin silencing further reduced cell proliferation compared with the control group and the negative control group (Fig. 5B). The percentage of apoptotic cells was examined by flow cytometry, and the apoptosis rate increased from $\sim 21$ to $45 \%$ after LY294002 was administered; moreover, the apoptosis rate of BXPC-3 cells was $33.95 \%$ following treatment with LY294002 alone and 20-39\% in PANC-1 cells treated with LY294002 alone (Fig. 5C). To further verify the relationship between Akt and Girdin, levels of Girdin and phosphorylated Girdin were detected by western blotting after LY294002 treatment to further verify the relationship between Akt and Girdin (Fig. 5D). Compared to the control group, the administration of LY294002 to block the PI3K/Akt pathway significantly decreased p-Akt levels, similar to the infection with rAd-shGirdin; furthermore, when we treated cells with both the LY294002 inhibitor and Girdin-siRNA adenoviruses, p-Akt levels were further reduced (Fig. 5D). No significant changes in 

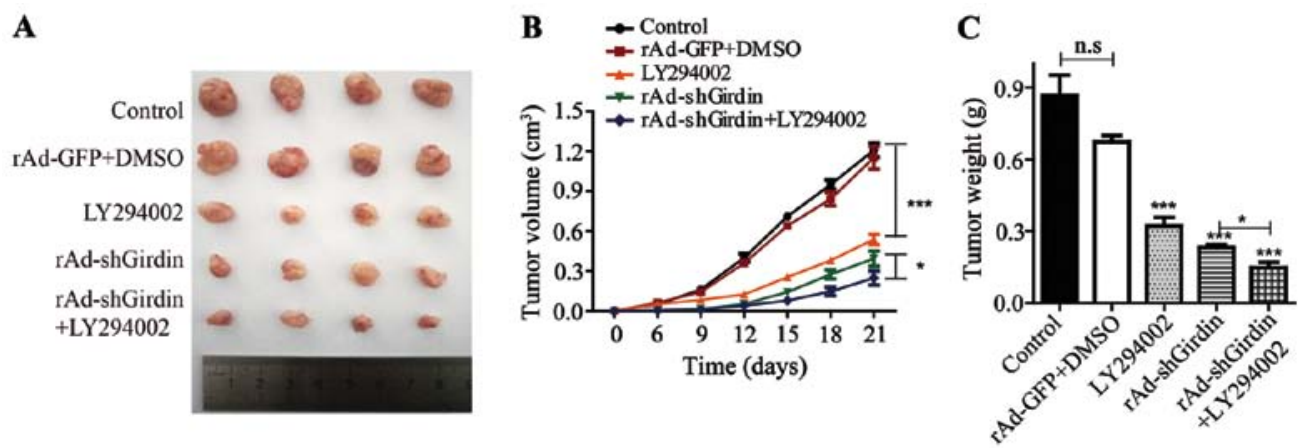

D
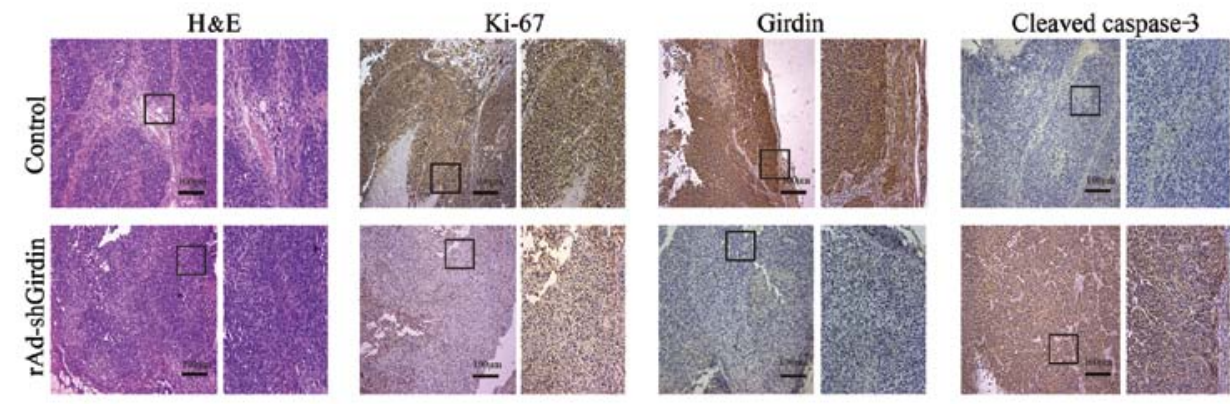

Figure 6. Girdin silencing suppresses pancreatic cancer growth and induces apoptosis in a xenograft model. (A) Representative data from xenograft tumours in mice in the different groups. (B and C) Statistical analysis of tumour volumes and weights in the different groups ( $\mathrm{n}=4,{ }^{*} \mathrm{P}<0.01$ and $\left.{ }^{* * *} \mathrm{P}<0.001\right)$. (D) Images of immunohistochemical staining using antibodies against Girdin, Ki-67 and cleaved caspase-3. n.s., not significant.

Table II. Relationship between the expression level of Girdin in PDAC tissues and the clinical characteristics of the patients.

\begin{tabular}{|c|c|c|c|c|}
\hline \multirow[b]{2}{*}{ Characteristics } & \multirow[b]{2}{*}{$\mathrm{n}$} & \multicolumn{2}{|c|}{$\begin{array}{l}\text { Girdin expression } \\
\text { in PDAC }\end{array}$} & \multirow[b]{2}{*}{ P-value } \\
\hline & & $\begin{array}{c}\text { Low } \\
\text { expression }\end{array}$ & $\begin{array}{c}\text { High } \\
\text { expression }\end{array}$ & \\
\hline Sex & & & & 0.808 \\
\hline Male & 46 & 40 & 6 & \\
\hline Female & 44 & 39 & 5 & \\
\hline Age (years) & & & & 0.189 \\
\hline$<60$ & 57 & 52 & 5 & \\
\hline$\geq 60$ & 33 & 27 & 6 & \\
\hline Pathological grade & & & & $0.014^{\mathrm{a}}$ \\
\hline $1-2$ & 55 & 52 & 3 & \\
\hline 3 & 35 & 27 & 8 & \\
\hline Clinical stage & & & & 0.146 \\
\hline $1-2$ & 78 & 70 & 8 & \\
\hline $3-4$ & 12 & 9 & 3 & \\
\hline
\end{tabular}

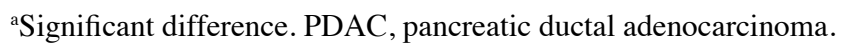

Akt levels were detected. Noteworthy, the data also showed that the level of phosphorylated Girdin (Ser 1416) was reduced in the LY294002 group, but no changes in the total Girdin level were observed. Subsequently, immunofluorescence staining was used to show that phosphorylated Girdin and Akt interacted and co-localized, particularly in the cytoplasm (Fig. 5E). Based on these data, we concluded that Girdin regulates cellular processes via the PI3K/Akt signalling pathway, and LY294002 enhances the effects of Girdin silencing; together, these treatments exert an additive effect on pancreatic tumour progression in vitro. Based on these results, Girdin plays a crucial role in pancreatic cancer cell processes via the PI3K/Akt signalling pathway, with the combined effects on each other.

Girdin silencing suppresses pancreatic cancer growth and induces apoptosis in a xenograft model. We subcutaneously injected nude mice with rAd-Girdin-infected BxPC-3 cells to further confirm the observed in vitro effects of Girdin on pancreatic cancer in vivo. As expected, Girdin silencing inhibited tumour growth in the xenograft mouse model, and the tumour-inhibiting capacity of Girdin silencing was further increased when LY294002 was administered concurrently (Fig. 6A-C). Subsequent immunohistochemical staining using antibodies against $\mathrm{Ki}-67$ and cleaved caspase-3 revealed that Girdin silencing suppressed pancreatic cancer proliferation and induced apoptosis in tissues from xenograft tumours (Fig. 6D), consistent with the in vitro results.

\section{Discussion}

Pancreatic cancer is one of the most malignant tumours in the world. Surgical resection is the only potentially curative treatment. Unfortunately, patient prognosis is poor, even after complete resection (16). Moreover, most drugs targeting specific molecules do not significantly prolong patient survival (17). Therefore, the focus of pancreatic cancer research is to identify new therapeutic targets.

Girdin has been reported to be a novel actin-binding protein that participates in the formation of the actin cytoskeleton and enhances Akt phosphorylation (4). Girdin has also been confirmed to be an oncogene that plays an important role 
in the occurrence and development of tumours (14); a great number of signalling pathways are involved in this process, including the PI3K/Akt signalling pathway. Girdin acts downstream of the PI3K/Akt signalling pathway and is directly activated by Akt (4). Girdin also binds to and activates Gai3, which further activates the PI3K/Akt signalling pathway (18), a classical signalling pathway that regulates tumour cell proliferation and apoptosis. Hence, Girdin may also be involved in this cellular process. However, the role of Girdin in pancreatic cancer has not been reported, and its function in pancreatic cancer development remains unclear.

In the present study, we first sought to examine Girdin expression in pancreatic cancer and its impact on pancreatic cancer. Girdin is expressed at high levels in PDAC tissues and cells and correlates with the degree of pancreatic cancer malignancy. Additionally, our microarray analysis revealed a relationship between the level of Girdin and the pathological grade; other researchers have also confirmed that Girdin expression is closely related to tumour malignancy, including the histological grade and metastasis, as well as progression-free survival (PFS) and overall survival (OS) (19). Thus, we believe that Girdin impacts pancreatic cancer development. The current study also has implications for our understanding of the role of Girdin as an oncogene in cancer cells, as Girdin knockdown impaired pancreatic cancer cell proliferation and induced apoptosis. Consistent with these findings, scientists have suggested that Girdin knockout inhibits cell proliferation (20). Girdin has also been shown to directly interact with Par-3, a cell polarity protein, to regulate cell polarity during cell migration (21). A positive correlation between Girdin and tumour cell motility has also been demonstrated $(22,23)$. Girdin silencing was recently shown to suppress glioma cell migration and invasion through the PI3K-Akt signalling pathway (24). Abnormal cell cycle progression leads to uncontrolled proliferation of tumour cells. Dysregulated apoptosis also results in tumourigenesis (25). Strategies that inhibit Girdin expression in HepG2 cells significantly reduce DNA synthesis, leading to an increase in apoptosis (11). Consistent with these findings, Girdin silencing increased pancreatic cancer cell apoptosis and induced cell cycle arrest in the present study. Moreover, Girdin silencing downregulated XIAP expression, reduced the Bcl-2/Bax ratio and increased levels of cleaved caspase-3. Of note, the PI3K/Akt pathway is also involved in cancer cell apoptosis via interactions with caspases and the Bcl-2 family (26). Thus, we hypothesized that Girdin influenced apoptosis via the PI3K/Akt pathway. As shown in the study by Anai Development of PI3K inhibitors: Lessons learned from early clinical trials. Nature reviews et al (11), a greater number of COS-7 cells expressing Akt and Girdin was found to undergo apoptosis, and fewer cells expressing Girdin underwent apoptosis; other scholars have proposed that Girdin depletion and Akt inactivation cooperate to induce HeLa cell apoptosis (7). According to Yamamura et al, Girdin is phosphorylated in cancer-associated fibroblasts during tumour progression (27). In the present study, Girdin silencing decreased the levels of p-Akt and p-PI3K, indicating that Girdin regulates the PI3K/Akt signalling pathway, as Girdin has been shown to promote PI3K phosphorylation, thereby activating the PI3K-Akt signalling pathway (28). We used LY294002 to inhibit the PI3K/Akt signalling pathway following infection with rAd-shGirdin in an attempt to investigate the underlying mechanism and found that LY294002 enhanced the effects of Girdin silencing, suggesting that Girdin regulates pancreatic cancer cell proliferation and apoptosis through the PI3K-Akt signalling pathway. In addition, we verified our results in an in vivo xenograft model, which produced similar results.

In conclusion, this study is the first to show that Girdin overexpression promotes pancreatic cancer cell proliferation and inhibits pancreatic cancer apoptosis; therefore, Girdin plays a role in the occurrence and development of pancreatic cancer. A PI3k/Akt pathway inhibitor has been tested in clinical trials, but some pharmacological questions remain. In addition, a combination therapy may be able to overcome the negative effects of PI3K pathway inhibition (29). However, further studies are required to determine whether Girdin will become an important therapeutic target for pancreatic cancer. Another limitation of our study is that we did not confirm whether Girdin and Akt directly interact or whether Girdin influences a potential regulator to modulate the PI3K/Akt pathway. The molecular mechanism by which Girdin regulates pancreatic cancer cell processes via the PI3K/Akt pathway will be studied further.

\section{Acknowledgements}

The authors thank Professor Doming Su and Miss Min Li for the technical support.

\section{Funding}

The present study was funded by grants from the National Natural Science Foundation of China (nos. 30972910 and 81172269) and the Natural Science Foundation of Jiangsu Province, China (no. 050104313).

\section{Availability of data and materials}

The datasets used during the present study are available from the corresponding author upon reasonable request.

\section{Authors' contributions}

SW and YL designed and conceived this study. SW and ZC performed the experiments, XY helped with animal experiments and cell culture, LL and XL were responsible for the statistical analysis of the results. SW and YL wrote the paper. CY reviewed and edited the manuscript, as well as provided funds and designed ideas. All authors read and approved the manuscript and agree to be accountable for all aspects of the research in ensuring that the accuracy or integrity of any part of the work are appropriately investigated and resolved.

\section{Ethics approval and consent to participate}

All animals received humane care, and all experiments were performed according to the guidelines outlined in the Guide for the Care and Use of Laboratory Animals, and our experiments were reviewed and approved by the Animal Ethics and Welfare Committee (AEWC) with approval no. IACUC-1601161. 


\section{Patient consent for publication}

Not applicable.

\section{Competing interests}

The authors state that they have no competing interests.

\section{References}

1. Siegel RL, Miller KD and Jemal A: Cancer Statistics, 2017. CA Cancer J Clin 67: 7-30, 2017.

2. Chen W, Zheng R, Baade PD, Zhang S, Zeng H, Bray F, Jemal A, Yu XQ and He J: Cancer statistics in China, 2015. CA Cancer J Clin 66: 115-132, 2016.

3. Wolfgang CL, Herman JM, Laheru DA, Klein AP, Erdek MA, Fishman EK and Hruban RH: Recent progress in pancreatic cancer. CA Cancer J clin 63: 318-348, 2013.

4. Enomoto A, Murakami H, Asai N, Morone N, Watanabe T, Kawai K, Murakumo Y, Usukura J, Kaibuchi K and Takahashi M Akt/PKB regulates actin organization and cell motility via Girdin/APE. Dev cell 9: 389-402, 2005.

5. Jiang P, Enomoto A, Jijiwa M, Kato T, Hasegawa T, Ishida M, Sato T, Asai N, Murakumo Y and Takahashi M: An actin-binding protein girdin regulates the motility of breast cancer cells. Cancer Res 68: 1310-1318, 2008.

6. Barbazan J, Dunkel Y, Li H, Nitsche U, Janssen KP, Messer K and Ghosh P: Prognostic impact of modulators of $\mathrm{G}$ proteins in circulating tumor cells from patients with metastatic colorectal cancer. Sci Rep 6: 22112, 2016.

7. Jiang P, Ren YL, Li JL and Luo J: Girdin expression in cervical carcinoma and its role in the malignant properties of HeLa cells. Oncol Lett 11: 2440-2444, 2016.

8. Miyake H, Maeda K, Asai N, Shibata R, Ichimiya H, Isotani-Sakakibara M, Yamamura Y, Kato K, Enomoto A, Takahashi $\mathrm{M}$ and Murohara T: The actin-binding protein Girdin and its Akt-mediated phosphorylation regulate neointima formation after vascular injury. Circ Res 108: 1170-1179, 2011.

9. Garcia-Marcos M, Ear J, Farquhar MG and Ghosh P: A GDI (AGS3) and a GEF (GIV) regulate autophagy by balancing G protein activity and growth factor signals. Mol Biol Cell 22: 673-686, 2011

10. Garcia-Marcos M, Jung BH, Ear J, Cabrera B, Carethers JM and Ghosh P: Expression of GIV/Girdin, a metastasis-related protein, predicts patient survival in colon cancer. FASEB J 25: 590-599, 2011.

11. Anai M, Shojima N, Katagiri H, Ogihara T, Sakoda H, Onishi Y, Ono H, Fujishiro M, Fukushima Y, Horike N, et al: A novel protein kinase B (PKB)/AKT-binding protein enhances PKB kinase activity and regulates DNA synthesis. J Biol Chem 280: 18525-18535, 2005.

12. Fresno Vara JA, Casado E, de Castro J, Cejas P, Belda-Iniesta C and González-Baron M: PI3K/Akt signalling pathway and cancer. Cancer Treat Rev 30: 193-204, 2004.

13. Mao Y, Xi L, Li Q, Cai Z, Lai Y, Zhang X and Yu C: Regulation of cell apoptosis and proliferation in pancreatic cancer through PI3K/Akt pathway via Polo-like kinase 1. Oncol Rep 36: 49-56, 2016.

14. Enomoto A, Ping J and Takahashi M: Girdin, a novel actin-binding protein, and its family of proteins possess versatile functions in the Akt and Wnt signaling pathways. Ann NY Acad Sci 1086 $169-184,2006$
15. Osaki M, Oshimura M and Ito H: PI3K-Akt pathway: Its functions and alterations in human cancer. Apoptosis 9: 667-676, 2004.

16. Fogel EL, Shahda S, Sandrasegaran K, DeWitt J, Easler JJ, Agarwal DM, Eagleson M, Zyromski NJ, House MG, Ellsworth S, et al: A multidisciplinary approach to pancreas cancer in 2016: A review. Am J Gastroenterol 112: 537-554, 2017.

17. Saif MW: Advanced stage pancreatic cancer: Novel therapeutic options. Expert Rev Clin Pharmacol 7: 487-498, 2014.

18. Ghosh P, Garcia-Marcos M, Bornheimer SJ and Farquhar MG: Activation of Galphai3 triggers cell migration via regulation of GIV. J Cell Biol 182: 381-393, 2008.

19. Gu F, Wang L, He J, Liu X, Zhang H, Li W, Fu L and Ma Y: Girdin, an actin-binding protein, is critical for migration, adhesion, and invasion of human glioblastoma cells. J Neurochem 131: 457-469, 2014

20. Cao K, Jiang W, Cao P, Zou Q, Xiao S, Zhou J and Huang C: Talen-mediated girdin knockout downregulates cell proliferation, migration and invasion in human esophageal carcinoma ECA109 cells. Mol Med Rep 10: 848-854, 2014.

21. Ohara K, Enomoto A, Kato T,Hashimoto T,Isotani-Sakakibara M, Asai $\mathrm{N}$, Ishida-Takagishi $\mathrm{M}$, Weng L, Nakayama $\mathrm{M}$, Watanabe $\mathrm{T}$, et al: Involvement of girdin in the determination of cell polarity during cell migration. Plos One 7: e36681, 2012.

22. Jun BY, Kim SW, Jung CK, Cho YK, Lee IS, Choi MG, Choi KY and Oh ST: Expression of girdin in human colorectal cancer and its association with tumor progression. Dis Colon Rectum 56: $51-57,2013$

23. Shibata T, Matsuo Y, Shamoto T, Hirokawa T, Tsuboi K, Takahashi H, Ishiguro H, Kimura M, Takeyama $\mathrm{H}$ and Inagaki $\mathrm{H}$ : Girdin, a regulator of cell motility, is a potential prognostic marker for esophageal squamous cell carcinoma. Oncol Rep 29: 2127-2132, 2013.

24. Ni W, Fang Y, Tong L, Tong Z1, Yi F, Qiu J, Wang R and Tong X: Girdin regulates the migration and invasion of glioma cells via the PI3K-Akt signaling pathway. Mol Medicine Rep 12: 5086-5092, 2015.

25. Arlt A, Müerköster SS and Schäfer H: Targeting apoptosis pathways in pancreatic cancer. Cancer Lett 332: 346-358, 2013.

26. Dan HC, Sun M, Kaneko S, Feldman RI, Nicosia SV, Wang HG, Tsang BK and Cheng JQ: Akt phosphorylation and stabilization of X-linked inhibitor of apoptosis protein (XIAP). J Biol Chem 291: 22846, 2004.

27. Yamamura Y, Asai N, Enomoto A, Kato T, Mii S, Kondo Y, Ushida K, Niimi K, Tsunoda N, Nagino M, et al: Akt-Girdin signaling in cancer-associated fibroblasts contributes to tumor progression. Cancer Res 75: 813-823, 2015.

28. Lin C, Ear J, Pavlova Y, Mittal Y, Kufareva I, Ghassemian M, Abagyan R, Garcia-Marcos M and Ghosh P: Tyrosine phosphorylation of the $\mathrm{G} \alpha$-interacting protein GIV promotes activation of phosphoinositide 3-kinase during cell migration. Sci Signal 4: ra64, 2011.

29. Rodon J, Dienstmann R, Serra V and Tabernero J: Development of PI3K inhibitors: Lessons learned from early clinical trials. Nat Rev Clin Oncol 10: 143-153, 2013.

This work is licensed under a Creative Commons Attribution-NonCommercial-NoDerivatives 4.0 International (CC BY-NC-ND 4.0) License. 